\title{
D.S.I.R. SUPPORT FOR UNIVERSITIES AND COLLEGES
}

\begin{abstract}
$D$ S.I.R., Universities and Colleges, 19.56-60* reviews the support given by the Department of Scientific and Industrial Research to research and postgraduate training in universities and colleges from August 1956 to December 1960. An introductory chapter outlines the functions and organization of the Department and summarizes the growth of support of this kind from 1929-30 to 1959-60. The two main chapters of the report, covering the training awards, studentships and fellowships, and the research grants are discussed on p. 605; a separate chapter reviews the support given to the human sciences, particularly the work of the Human Sciences Committee, and its sub-committees, which in 1958-60 considered 75 applications and by July 1960 had recommended more than 38 awards at an estimated cost of $£ 193,000$. Besides the figures given in the report itself appendixes, numbering some 100 pages, include, besides particulars of membership of the Council and its Committees and Sub-committees, statistics of studentships, fellowships and of research grants for the period.

In 1960 the Department awarded 942 research studentships, 274 advanced course studentships, 77 first-year studentships and 39 fellowships. Of the research studentships $13 \cdot 3$ per cent were in biology and biochemistry; 7 per cent in chemical engineering and metallurgy; $25 \cdot 7$ per cent in chemistry; $4 \cdot 2$ per cent in electrical engineering; $7 \cdot 6$ per cent in other engineering; $6 \cdot 6$ per cent in geology; 2.4 per cent in

* Department of Scientific and Industrial Research. D.S.I.R., Universities and Colleges, 1956-60: a Report on D.S.I.R. Support for Research and Training in Universities and Colleges, 1956-60. Pp. viii $+232+15$ plates. (London: H.M.S.O., 1962.) 15s. net. (see also p. 605 of this issue.)
\end{abstract}

human sciences; $11 \cdot 6$ per cent in mathematics; and 21.5 per cent in physics. Over the period 1957-60 the corresponding percentage figures for new advanced course studentships are: $8.8 ; 9.9 ; 1.5 ; 7.3 ; 15.0$; $10 \cdot 2 ; 7 \cdot 7 ; 22 \cdot 6 ; 17 \cdot 2$. Only 20 students and 17 Fellows from the United Kingdom held their awards abroad in 1959-60 and 26 and 30, respectively, in 1960-61, but over the period 1957-60 there was a slight but steady increase in migration of research students between universities and in 1960,19 per cent of research students and first year students migrated on taking up an award in Britain. There was a marked movement away from the colleges of advanced technology and the technical colleges and the likelihood of migration varied with the subject of research. Of 467 research students whose awards terminated in the year ended September 30, 1959, 99 took up overseas posts; 91 posts in industry, 79 research posts and 57 teaching posts in universities, 25 posts in the Scientific Civil Service and 18 in technical colleges.

Of research grants awarded during October 1956September $1960, £ 409,783$ was in astronomy, $£ 400,139$ in biology, $£ 750,820$ in chemistry, $£ 326,267$ in geology, $£ 640,169$ in low-temperature and solid-state physics, $£ 10,125$ in mathematics, $£ 2,655,108$ in nuclear physics, $£ 288,501$ in other physics, $£ 627,812$ in technology, $£ 225,326$ in human sciences and $£ 297,543$ in space research. Of the total of $£ 6,631,943$ all except $£ 189,493$ was to universities.

A section of the chapter in the report dealing with research grants reviews some of the results obtained from the Department's support of research in the various fields during the past four years.

\section{REPORT OF THE GOVERNMENT CHEMIST FOR 1961}

$I^{\mathrm{N}}$ his recently published report*, Dr. D. T. Lewis, the Government Chemist, describes the wide range of work done in his Laboratory during 1961. During that period an average of more than 1,000 samples were analysed or otherwise examined every working day. These included such materials as manufactured fabrics, tobaccos, wines, spirits, drugs, foodstuffs, and a wide variety of inorganic and organic chemicals, which might, for example, occur in chemical formulations of pesticides, fertilizers and animal feeding stuffs. Almost all the work has been done at the request of various Government Departments in the United Kingdom, but some Commonwealth countries and Colonial Administrations have also availed themselves of the services offered by the Laboratory.

A great deal of the Laboratory's time is spent on various statutory duties, principally in collaboration with H.M. Customs and Excise; this is a reminder that the Laboratory was originally created by the Board of Inland Revenue in $\mathbf{1 8 4 2}$ for the purpose of aiding the revenue authorities to detect and prevent infringements of the various Customs and Excise

* Department of Scientific and Industrial Research: Laboratory of the Government Chemist. Report of the Government Chemist, 1961. Pp. $v+89+3$ plates. (London: H.M.S.O., 1962.) 6s. 6d. net. regulations which deal with dutiable commodities such as tobacco, beers, wines and spirits, and sugar. Although this basic work of the Laboratory changes little from year to year, nevertheless alterations and additions to its general work have to be made in accordance with the changing laws of the country. The Laboratory has constantly to be on the look-out for new forms of tax evasion, intentional or otherwise, on materials where the duty liability, particularly to purchase tax, is more readily avoided. New fiscal measures can, of course, create new problems for the Laboratory which must be ready to help with the implementation of the new laws by providing suit. ably accurate and reliable methods of analysis for the materials in question. An example of this is given in the Finance Act of 1960 , which requires certain marker substances to be added to gas oils sold for purposes other than road use. The Laboratory has had to develop analytical methods for the detection and determination of these additives (furfural and quinalizarin) in this type of fuel oil, and satisfactory procedures have recently been published.

A small but increasing amount of forensic work is done principally for the General Post Office and mainly involves the examination of questioned 